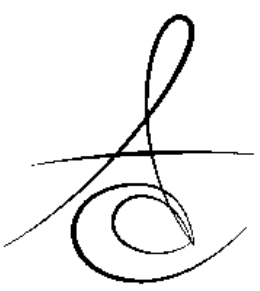

\title{
OSTEOGENEZİS İMPERFEKTA HASTASININ DİŞ TEDAVİSİ: BİR OLGU SUNUMU
}

\section{DENTAL TREATMENT OF A PATIENT WITH OSTEOGENESIS IMPERFECTA: A CASE REPORT}

\author{
Dr.Öğr.Üyesi Aslı SOĞUKPINAR ÖNSÜREN*
}

Dr.Öğr.Üyesi Ömer HATİPOĞLU**

Makale Kodu/Article code: 4329

Makale Gönderilme tarihi; 25.02 .2020

Kabul Tarihi: 13.08 .2020

DOI : $10.17567 /$ ataunidfd. 780178
Aslı Soğukpınar Önsüren: ORCID ID: 0000-0002-1934-9945

Ömer Hatipoğlu: ORCID ID: 0000-0002-4628-8551

\section{öz}

Osteogenezis İmperfekta 'kırılgan kemik hastalığı' kemik kırılganlığında artma ve iskeletsel deformiteler ile ilişkilendirilmektedir. Bu hastalarda aile öyküsü, mavi sklera, duyma kaybı, dentinogenezis imperfekta gibi belirgin klinik özellikler gözlenebilmektedir. Bu vakada Kahramanmaraş Sütçü İmam Üniversitesi Çocuk Diş Hekimliği Bölümü'nde tedavi edilen 11 yaşındaki Osteogenezis İmperfekta'ı kız hasta sunulmaktadır. Hastanın yüzünde asimetri ve üçgensel form, boy kısalığı, pektus ekskavatum veya karinatum gibi göğüs duvarında ve ayaklarında deformiteler tespit edilmiştir. Hastanın klinik ve radyografik muayenesi sonucunda çürük dişlerine dolgu uygulamıştır.

Hastamız çocuk diş hekimliği ve ortodonti bölümünde düzenli aralıklarla kontrol altındadır.

Anahtar Kelimeler: Osteogenezis İmperfekta, çocuk, diş tedavisi

\section{ABSTRACT}

Osteogenesis Imperfecta 'brittle bone disorder' is associated with bone fragility and skeletal deformities. Significant clinical features such as family history, blue sclera, hearing loss, dentinogenesis imperfecta may be observed in these patient.

This article reports a case of Osteogenesis Imperfecta in a eleven-year-old female patient treated in Kahramanmaraş Sütçü Imam University, Department of Pediatric Dentistry. Asymmetry and triangular form of the patient's face, short stature, pectus excavatum or carinatum deformities on chest wall and feet were detected. The clinic signs and symptoms of the patient were detected and the treatment plan was analyzed. In routine clinic dental examination and filling and protective applications were successfully applied.

The patient is still under regular control by pediatric and orthodontic department.

Key Words: Osteogenesis Imperfekta, child, dental treatment

${ }^{*}$ Kahramanmaraş Sütçü İmam Üniversitesi, Diş Hekimliği Fakültesi, Pedodonti Anabilim Dalı Kahramanmaraş

${ }^{* *}$ Niğde Ömer Halis Üniversitesi, Diș Hekimliği Fakültesi, Restoratif Diș Tedavisi Anabilim Dalı Niğde

\footnotetext{
Kaynakça Bilgisi: Soğukpınar Önsüren A, Hatipoğlu Ö. Osteogenezis imperfekta hastasının diş tedavisi: bir olgu sunumu. Atatürk Üniv Diş Hek Fak Derg 2021; 31: 275-8.

Citation Information: Sogukpinar Onsuren A, Hatipoglu O. Dental treatment of a patient with osteogenesis imperfecta: a case report. J Dent Fac Atatürk Uni 2021; 31: $275-8$.
}

\section{GİRİs}

Osteogenezis İmperfekta (Oİ) 'kırılgan kemik hastalığı' veya 'cam kemik hastalığı' olarak da ifade edilen, kemik frajilitesinde artma ve kemik kütlesinde azalma ile karakterize 15-20.000 doğumda bir görülen kalıtımsal bağ dokusu rahatsızlığıdır.1,2 Oİ rahatsızIığına sahip bireylerin \%90'ında tip I kollajeni kodlayan genlerde (COLIA1 ve COLIA2) mutasyon varlığı tespit edilmiştir.3,4 Tip 1 kollajen; kemik, deri ve tendonların ekstrasellüler yapısını oluşturan ana yapısal protein olan iki pro-1 zinciri ve bir pro-2 zincirinden meydana gelen rijit üçlü sarmal proteindir. Bu nedenle hastalarda kemik, tendon, deri, sklera ve dentini ilgilendiren problemlere rastlanılır. ${ }^{5}$ Hastalığın teşhisi; aile öyküsü, klinik ve genetik testlerle konulur. ${ }^{2}$

Söz konusu rahatsızlığın ekstraoral klinik özelliklerinde; mavi sklera, dentinogenesis imperfekta (Dİ), üçgensel yüz, duyma kaybı (orta kulak patolojisi nedeniyle), eklem hipermobilitesi, kardiyovasküler rahatsızlık, kas zayıflığı, çoklu kırıklar ve kafatasındaki kemiklerde deformite varlığı yer almaktadır. ${ }^{1}$

Oİ hastalarının yaklaşık \%50'sinde dişsel anomaliye rastlanılmaktadır. ${ }^{6}$ Hastaların dişlerinde grimsi- 
maviden kahverengiye kadar renk değişimi, kısa kron ve kök veya pulpa obliterasyonu ile karakterize Dİ varlığı da görülebilmektedir. ${ }^{7}$ Söz konusu hastalığa sahip bireylerde en çok görülen dişsel anomali hipodontidir. ${ }^{8}$ Ayrıca hastalarda gömülü dişler ${ }^{9}$, mandibular overjete bağlı Class 3 malokluzyon, anterior ve posterior çapraz veya açık kapanış varlığı izlenebilmektedir. ${ }^{10}$

Literatürde hastalığın sınıflandırılması ilk kez Sillence ve ark. tarafından; Oİ tip I: 'hafif form', mavi sklera ve otozomal dominant geçişli, progresif deformite yok; Oİ tip II:' öldürücü form', otozomal resesif geçişli; Oİ tip III: 'ciddi form', progresif kemik deformiteleri ve karakteristik yüz, otozomal resesif geçişli, Oİ tip IV: fenotipi Oİ tip I ve III arasında, daha az tanımlanabilen form diye sınıflandırıır. ${ }^{11}$ Daha sonra Glorieux ve ark. tarafından farklı bir otozomal dominant geçişli Oİ tip $\mathrm{V}^{12}$ ve otozomal resesif geçişli tip VI-XV literatüre sunulmuştur. 4, 13- 15

Bu vaka sunumunun amacı diş tedavisi yapılan oİ hastası hakkında bilgi vermektir.

\section{OLGU SUNUMU}

11 yaşındaki kız hasta, 2019 yılında Kahramanmaraş Sütçü İmam Üniversitesi Diş Hekimliği Fakültesi Pedodonti Anabilim Dalı́na ön bölgedeki çürük dişlerinden kaynaklanan estetik ve ağrı problemleri nedeniyle başvurmuştur. Çocuğun tıbbi anamnezine göre, Oİ teşhisinin Tıp Fakültesi Tıbbi Genetik tarafından konulduğu, geçmişinde çoklu ve tekrarlayan kemik kırıkları olduğu ve bifosfonat (Pamidronat) kullandığı öğrenilmiştir. Aile öyküsünde ise 3 yaşındaki erkek kardeşinin de Oİ hastası olduğu belirtilmiş, anne ve babada söz konusu hastalığın yer almadığı görülmüştür. Hastanın klinik bulguları oldukça açık olup, ekstraoral muayenesi yapıldığında; zayıf ve ince yapılı olduğu, mavi sklera, yüzünde asimetri ve üçgensel form, boy kısalığı, pektus ekskavatum veya karinatum gibi göğüs duvarında ve ayaklarında deformiteler gözlenmiş, yürüme aktivitesini gerçekleştiremediği tespit edilmiştir (Resim 1A-B). Erkek kardeşinde de benzer şekilde mavi sklera varlığı ve çoklu ve tekrarlayan kemik kırıkları olduğu öğrenilmiştir.

Hastadan ağız içi fotoğraflar ve panoramik radyografi alınmıştır. Klinik ve radyografik muayene sonucunda \#11, 21, 22, 53, 14, 26, 46 nolu dişlerinde çürük; \#44,34 nolu dişlerde mikrodonti izlenmiştir (Resim 2A-B). Bununla birlikte dişlerde renk bozukluğu gözlenmemiştir. Hastada daimi diş eksikliğinin olmadığı panoramik radyografide doğrulanmıştır (Resim 3). Hastanın kapanışı kontrol edildiğinde overjite, openbite ve Class 3 malokluzyon varlığı saptanmıştır.

Tıp Fakültesi ile konsültasyon yapılmasının ardından hastanın koopere olduğu gözlendiğinden diş tedavisinin planlamasına geçilmiştir. \#11, 21, 22, 53, 14, 26, 46 dişlerinin restorasyonu self-etch bond (3M Adeziv 200T, St. Paul. MN, USA) uygulanması sonrasında kompozit (3M Adeziv 200T, St. Paul. MN, USA) restorasyonu ile yapılmıştır. \#44, 34, 15 nolu dişlere fissür örtücü (3M ESSE Clipro, St.Paul. MN, USA) uygulanmıştır. Yerel flor uygulaması \%1,23'lük APF (Sultan Topex APF gel, Sultan Dental Products, USA) ile gerçekleştirilmiştir (Resim 4). Hasta düzenli kontrollere çağırılmış, ortodonti kliniğiyle birlikte kliniğimizde kontrol altındadır.
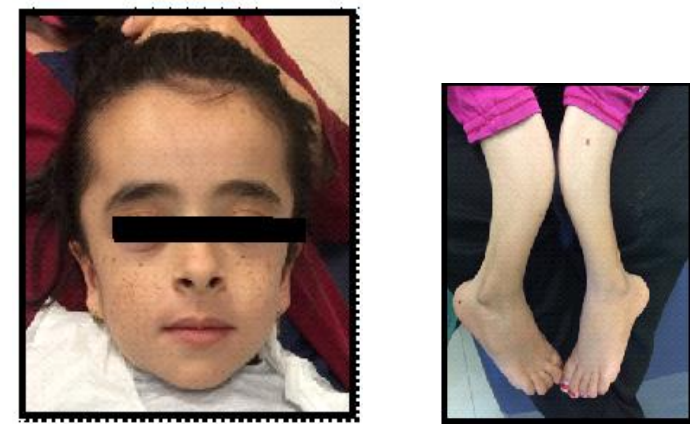

Resim 1A-B. Olgunun ekstraoral görünümü

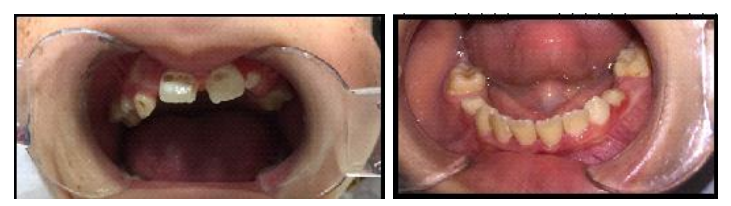

Resim 2A-B. Hastanın tedavi öncesi ağız içi görünümü

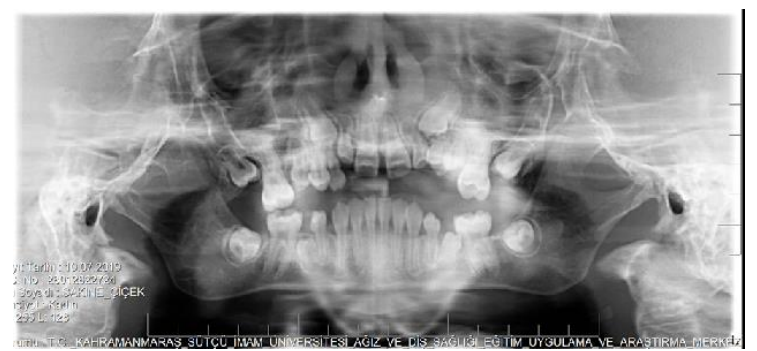

Resim 3. Olgunun panoramik radyografisi 


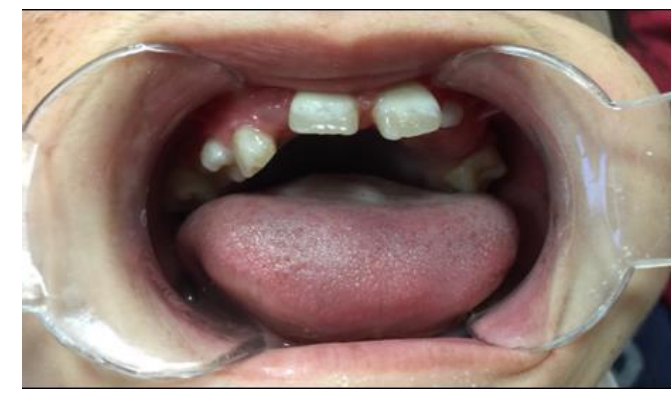

Resim 4. Hastanın tedavi sonrası ağız içi görünümü

\section{TARTIŞMA}

Oİ hastalığının teşhisi klinik ve radyografik bulgulara dayanmakta ve multidisipliner tedavi yaklaşımı gerekmektedir. ${ }^{11}$ Yaşa ve hastalığın ciddiyetine bağlı olarak uzun kemiklerde eğilmeler, omurga eğriliği, pektus ekskavatum veya karinatum gibi göğüs kafesinde deformiteler, kemik kırılganlığına yatkınlık gibi iskeletsel rahatsızlıklara rastlanılmaktadır. ${ }^{3}$ Ayrıca hastalarda mavi sklera, Dİ, işitme kaybı, eklem hipermobilitesi, kısa boy, azalmış pulmoner fonksiyon ve kalp kapak yetmezliği gibi iskeletsel olmayan rahatsızlıklar da saptanabilir. ${ }^{4}$ Bizim hastamızda da mavi sklera, yüz asimetrisi ve üçgensel form, boy kısalığı, omurga eğriliği, göğüs kafesinde deformite varlığı, bacak kemiklerinde eğrilik izlenmektedir. Hastada gözlemlediğimiz belirtiler doğrultusunda kesin olmamakla beraber vakamızın Oİ tip I olduğu kanısındayız. Alınan anamnez sonucunda hastamızın geçmişinde çoklu ve tekrarlayan kemik kırıkları bulunduğu, cerrahi müdahaleye gerek kalmadan kırıkların tedavi edildiği öğrenilmiştir.

Oİ hastaları kemik densitesini arttırdığı ve söz konusu hastalığın ilerlemesini yavaşlattığı için bifosfanat veya antirezorptif ilaç kullanabilmektedir. İlacın temel mekanizması osteoklastların fonksiyonunu inhibe ederek kemik rezorbsiyonunu ve kemik ağrılarını engellemektedir. ${ }^{16}$ Benzer şekilde alınan anamnez sonucu hastamızın bifosfanat kullandığı öğrenilmiştir. Literatürde bifosfonat kullanımının diş sürmesini ve gelişmesini yavaşlattığı ${ }^{17}$ sunulmuş olmasıyla birlikte bizim vakamızda diş sürmesinin normal seyrinde ilerlediği görülmüştür.

Literatürde Oİ hastalarında Dİ bulguları gözlenen vaka olduğu kadar $^{18}$, söz konusu bulguları taşımayan vakalar da yer almaktadır. ${ }^{19}$ Bizim vakamızda da klinik ve radyografik muayene sonucunda hastamızda dişlerde şekil ve renk değişimi, pulpa odasında daralma vb. gibi Dİ varlığına rastlanılmamıştır. Bununla birlikte hastanın bazı dişlerinde mikrodonti varlığı tespit edilmiştir.

Oİli hastalarda çürüğe ve periodontal problemlere yatkınlık gözlenebilmektedir. Söz konusu rahatsızlığa sahip hastaların tedavilerinin olabildiğinde konservatif yöntemlerle yapılması gerektiği literatürde belirtilmiştir. ${ }^{20}$ Hastaların ağız ve diş sağlığının zayıf olması diş ağrılarına yol açtığından tedavileri yapılmalıdır. Bu amaçla bizim vakamızda da hastamızın çürük dişleri kompozit rezin ile restore edilmiş, koruyucu uygulamalar özenle gerçekleştirilmiştir. Ayrıca literatürde hastaların çürük dişlerinin restorasyonu amacıyla paslanmaz çelik kronun da (PÇK) tercih edildiği görülmüş ve hastanın okluzyonunun yükseltilmesi tedavi seçeneği olarak kullanıımıştır. ${ }^{21}$ Hastamızın tedavileri kliniğimizde başarıyla gerçekleştirilmiş olup, hastamız ağız ve diş sağlığını korumak adına düzenli takiplerle pedodonti ve ortodonti kliniğimizde kontrol altındadır.

Bu çalışma, çalışmayı yürüten tüm yazarlar tarafından okunmuş ve onaylanmış orijinal bir çalışmadır. Herhangi bir yazar, kurum ya da kuruluş ile çıkar çatışması olmadığını belirtilmek isteriz.

\section{KAYNAKLAR}

1. Glorieux FH. Osteogenesis imperfecta. Best Pract Res Clin Rheumatol 2008; 22:85-100.

2. Marini JC, Forlino A, Cabral WA et al. Consortium for osteogenesis imperfecta mutations in the helical domain of type I collagen: regions rich in lethal mutations align with collagen binding sites for integrins and proteoglycans. Hum Mutat 2007; 28:209-21.

3. Forlino A, Marini JC. Osteogenesis imperfecta. Lancet 2016; 387:1657-71.

4. Forlino A, Cabral WA, Barnes AM, Marini JC. New perspectives on osteognesis imperfecta. Nat Rev Endocrinol 2011; 7:540-57.

5. Cole WG. The molecular pathology of osteogenesis imperfecta. Clin Orthop Relat Res 1997; 343:23548.

6. Patel RM, Nagamani SC, Cuthbertson D, et al. A cross sectional multi-centred study of osteogenesis imperfecta in North America. Clin Genet 2015; 87:133-40.

7. Barron MJ, McDonnell ST, MacKie I, Dixon MJ. Hereditary dentine disorders: dentinogenesis imperfecta and dentine dysplasia. Orphanet J Rare Dis 2008; 3:31. 
8. Malmgren B, Norgren S. Dental aberrations in children and adolescents with osteogenesis imperfecta. Acta Odontol Scand 2002; 69:65-71.

9. Waltimo-Siren J, Kolkka M, Pynnönen S, Kuurila K, Kaitila I, Kovero O. Craniofacial features in osteogenesis imperfecta: a cephalometric study. Am J Med Genet A 2005; 133:142-50.

10. Stenvik A, Larheim TA, Storhaug K. Incisor and jaw relationship in 27 persons with osteogenesis imperfecta. Scand J Dent Res 1985; 93:56-60.

11. Sillence DO, Senn A, Danks DM. Genetic heterogeneity in osteogenesis imperfecta. J Med Genet. 1979; 16:101-16.

12. Glorieux FH, Rauch F, Plotkin H, Ward L, Travers $R$, Roughley $P$, et al. Type $V$ osteogenesis imperfecta: a new form of brittle bone disease. J Bone Miner Res 2000; 15:1650-8.

13. Bishop N. Characterising and treating osteogenesis imperfecta. Early Hum Dev 2010; 86:743-6.

14. Kovero O, Pynnönen S, Kuurila-Svahn K, Kaitila I, Waltimo- Sirén J. Skull base abnormalities in osteogenesis imperfecta: a cephalometric evaluation of 54 patients and 108 control volunteers. J Neurosurg 2006; 105:361-70.

15. Semler O, Garbes L, Keupp K, Swan D, Zimmermann K, Becker J, et al: A mutation in the 5 -UTR of IFITM5 creates an in-frame start codon and causes autosomal-dominant osteogenesis imperfecta type $\mathrm{V}$ with hyperplastic callus. Am J Hum Genet 2012; 91:349-57.

16. Dwan K, Phillipi CA, Steiner RD, Basel D. Bisphosphonate therapy for osteogenesis imperfecta. Cochrane Database Syst Rev 2014; 23:CD005088.

17. Bradaschia-Correa V, Massa LF, Arana-Chavez VE. Effects of alendronate on tooth eruption and molar root formation in young growing rats. Cell Tissue Res 2007; 330:475-85.

18. Foster BL, Ramnitz MS, Gafni RI, et al. Rare bone diseases and their dental, oral, and craniofacial manifestations. J Dent Res 2014; 93:7-19.

19. Lindau B, Dietz W, Lundgren T, Storhaug K, Noren JG. Discrimination of morphological findings in dentine from osteogenesis imperfecta patients using combinations of polarized light microscopy, microradiography and scanning electron microscopy. Int J Paediatr Dent 1999; 9:253-61

20. Öztunç $H$, Üstün Y. Osteogenezis Imperfekta: bir olgu raporu. Cumhuriyet Üniv Diş Hek Fak Derg 2000; 3:133-5.
21. Gürbüz T, Özbek MS, Özbek E. Osteogenezis Imperfekta: Bir Olgu Sunumu. Atatürk Üniv Diş Hek Fak Derg 2007; 3:48-51.

\section{Sorumlu Yazarın Yazışma Adresi}

Dr. Öğretim Üyesi ASLI SOĞUKPINAR ÖNSÜREN

Kahramanmaraş Sütçü İmam Üniversitesi, Diş Hekimliği Fakültesi, Pedodonti Anabilim Dalı Kahramanmaraş/Türkiye

Telefonu: 05076014870

E-maili: aslisdt@gmail.com 